\title{
EDUCATION OF TRIBAL COMMUNITIES IN KERALA
}

\author{
Dr. Asha C M. \\ Senior Research Fellow (ICSSR), New Delhi. \\ DOI: 10.46609/IJSSER.2020.v05i06.001 URL: https://doi.org/10.46609/IJSSER.2020.v05i06.001
}

\begin{abstract}
Education is the most important element in the development of any community. India has the largest concentration of the tribal population in the world. The government has implemented many policies and programmes for the development of education of the tribal community. They are yet to reap the benefits of these policies and programmes and lag far behind the mainstream population. In Kerala, although the overall educational development indices are much above the national level, the disparity in educational attainment in tribal communities still continues and remains a dilemma. The study attempts to explore the state of affairs of education of tribals in Kerala. The present study on education of tribes in Kerala particularly concentrates on issues such as low literacy level of tribal community and high dropout rate of tribal students. The investigation reveals the educational challenges of tribal students and highlights the reasons for their school dropout. Various suggestions to improve the tribal education are formulated. The study poses significant implications in the improvement of tribal education.
\end{abstract}

Keywords: Education, Kerala, Tribal communities

\section{INTRODUCTION}

India has the largest concentration of the tribal population in the world. Tribals constitute $8.61 \%$ of the total population of the country, numbering 104.28 million and cover about $15 \%$ of the country's area. India is a home to 711 tribal groups spread all the states and union territories. South India accounts for slightly over 11 percentage of tribal population (2011 Census). The tribes in India with their rich cultural inheritance are a fundamental part of our national life. The greatest challenge that the Government of India has been facing since independence is the right provision of social justice to the scheduled tribe people as they constitute the weakest section of India's population, from the education, ecological, economic and health angles. This could owe to their specific beliefs and practices or the ill-reach of various government benefits to improve 


\section{International Journal of Social Science and Economic Research}

the living standards of these people. The fact that tribal people need special attention can be observed from their low social, economic and participatory indicators. Since the tribal communities reside, normally, in the remote interiors which are inaccessible and therefore under developed. Moreover, they live in small habitations without basic infrastructures like transportation and communication. Besides they have their own structural impediments which make them deprived and excluded with regard to almost everything that a contemporary mainstream society has. Whether it is education, size of agricultural holdings, access to drinking water and electricity or maternal and child mortality, tribal communities lag far behind the general population. The government has implemented many policies and programs for development of the tribal community. But, they are yet to reap the benefits of these policies and programmes (Kolay and Bairagi, 2013).

Education is the most important element in the development of any community, particularly, tribal areas. Education helps to bridge the gap of disparities between people, socio-economic groups and region. It develops human resources, which has a multiplier effect on utilization of all other resources. Education is a powerful indicator of social and economic development among the backward groups including tribes (Mitra and Singh, 2006). Despite several programmes implemented towards the provision of compulsory education, especially for SCs/STs, the illiteracy rate continues to be quite high among them.

\section{STATEMENT OF THE PROBLEM}

Kerala is regarded as an educationally forward State compared to other States in India. This is marked by high levels of literacy rate, improved enrolment of students etc. (Naidu and Nair, 2007). Though the overall educational development indices were much above the national level, the disparity in educational attainment between non-SC/ST populations and tribal communities still continues and remains a dilemma. Educating the weaker section of our society including the tribals is very important as education is a necessary pre-condition for socio economic development and a crucial element in sustaining the social exclusion. The comparison between literacy rates among Scheduled Tribes also shows a huge disparity. These variations are a reflection of the differences in economic, social, cultural, religious and demographic characteristics of the different tribes and their exposure to the forces of modernization, urbanization and industrialization (Mitra and Singh, 2008).

The tribal dropout rate is high compared to SCs and general population. Despite the government initiatives, including the Tribal Sub-Plans (TSP) giving great emphasis on the education of tribals, the problem of educational dropouts is high among the tribes compared to the mainstream population (Mitra and Singh, 2008).The researcher tries to identify the exact problems facing tribal education of Kerala. The present study on education of tribes in Kerala particularly 
concentrates on issues such as low literacy level and high dropout rate of students. In the contemporary scenario, it is vital to make an investigation into the problems of tribal students and suggest solutions to improve the situation.

\section{OBJECTIVES OF THE STUDY}

The main objective of the study is to understand the problems of tribal education in Kerala, and to make suggestions for the improvement of the education of tribals.

The specific objectives are:

- To understand the socio demographic profile of the respondents.

- To analyse the education among the tribes in Kerala.

- To compare and analyse education of tribes with other social groups

- To identify social, economic, cultural and institutional factors of the tribes determining the dropout from education.

\section{METHODOLOGY}

\subsection{Research design and Sampling design}

The research design adopted is descriptive design. The sampling design adopted is stratified random sampling. The area of this present study is confined to 3 districts: Wayanad, Palaghat and Idukki districts are identified for study. These three districts are the hilly regions and tribal dominated districts. Wayanad ranks first in tribal population in Kerala about 31 percent of total tribal population of the state. Six tribal group namely Adiya, Kattunaika, Mullakuruma, Vettakuruma, Paniya, and Kurichiya are the major tribal groups in Wayanad district . Idukki ranks second among the district of Kerala in tribal population with 11 percent (2011census). Three castes namely Mannan, Muthuvan and Hillpulaya are the major tribal groups of Idukki . Out of the different panchayaths in the district, 2-3 of them selected on the availability of dominant tribal groups. The young children among the tribal communities in the State who are constrained from going on with their formal education and the students continuing with their studies at $9^{\text {th }}$ or $10^{\text {th }}$ level constitute the population for the present study. Sample size is 150 .

\subsection{Data collection and Analysis}

Primary data is collected by interview schedule. The primary data on the socio demographic profile and challenges faced by tribal students are collected by in depth interview .Secondary data is collected from journals, published articles, magazines, internet sources and newspapers. 
Besides, unpublished data are gathered from research organizations/institutions, government sources etc. Data is analysed by SPSS.

\section{MAJOR FINDINGS}

The analysis of secondary data revealed that, there exist a significant gap in literacy rate between the general and STs for all the census years staring from 1961 to 2011.

\subsection{Literacy of Scheduled Tribes and General State Average}

\begin{tabular}{|c|c|c|c|c|c|c|}
\hline Year & $\mathbf{1 9 6 1}$ & $\mathbf{1 9 7 1}$ & $\mathbf{1 9 8 1}$ & $\mathbf{1 9 9 1}$ & $\mathbf{2 0 0 1}$ & $\mathbf{2 0 1 1}$ \\
\hline General Literacy & 55.08 & 69.75 & 78.85 & 89.81 & 90.92 & 93.91 \\
\hline ST Literacy & 17.26 & 25.72 & 31.79 & 57.22 & 64.35 & 75.81 \\
\hline Gap in Literacy & 37.82 & 44.03 & 47.06 & 32.59 & 26.57 & 18.10 \\
\hline
\end{tabular}

Source: Census of India, (1961 - 2011)

Table 5.1: Literacy of Scheduled Tribes and General State Average

The analysis of secondary data reveals that, there exist significant difference in the literacy rate of general population and ST's. The policies aimed at improvement in literacy rate have made only a dawdling progress which is evident from the wide disparity existing between the literacy rates of general population and STs.

\subsection{Gender-wise General and ST Literacy Rate}

\begin{tabular}{|c|c|c|c|c|c|c|}
\hline Year & \multicolumn{3}{|c|}{ General literacy } & \multicolumn{3}{c|}{ ST Literacy Rate } \\
\hline $\mathbf{2 0 0 1}$ & 90.86 & 94.24 & 87.72 & 64.40 & 70.80 & 58.10 \\
\hline $\mathbf{2 0 1 1}$ & 93.91 & 96.02 & 91.98 & 75.81 & 80.76 & 71.08 \\
\hline
\end{tabular}

Table 5.2: Gender-wise General and ST Literacy Rate.

The analysis of secondary data revealed that, there exist significant gender disparities in literacy rate within the STs.

\subsection{Educational attainment of Scheduled Tribes in Kerala}




\section{International Journal of Social Science and Economic Research}

ISSN: $2455-8834$

Volume: 05, Issue: 06 "June 2020"

According to study conducted by Scheduled Tribes Development Department, (2013), about 80.7 percent of the literates have education below 10th level only 11.2 percent of literates have attained education up to matriculation level. Percentage of tribes with plus-two degree is 6.02. The tribes with high level of education i.e. above graduation are only just above 2 percent of the literates From this data, it is obvious that tribes lag much behind other social groups of Kerala in the attainment of higher levels of education..

\subsection{Socio demographic profile of the respondents}

Considering the age of the respondents,3.3\% of respondents are aged 11 years, $21.7 \%$ of respondents are aged 12 years , 28.3\% of respondents are aged 13 years , 30.0\% of respondents are aged $14,12.2 \%$ of respondents are aged 15 years $.4 .5 \%$ of the respondents belong to the age group 16-18.

$38.4 \%$ of the respondents are males and $61.6 \%$ of the respondents are females.

The analysis reveal that, $23.3 \%$ of the respondents are Christians and $76.7 \%$ are Hindus.

Different tribal groups live in Wayanad and Idukki districts. 25.0\% of respondents are Ulladan, $21.7 \%$ of respondents are Urali, $23.3 \%$ of respondents are Mala Arayaran. $10.1 \%$ are Malai Pandaran, 17. 6\% are Malai Vedan, $2.3 \%$ are Paniyan.

Occupation of parents positively influences the academic achievement of child (Bala, 2011). The educational level as well as employment status of the parents has substantial influence on the education of their children. Considering the education of the father of respondents, $33.3 \%$ have gone to primary school,43.7\% have completed primary school education, $12.2 \%$ have studied in highschool.10.8\% have completed high school. None of the fathers of respondents have studied above high school.13.7\% of mothers of respondents have not gone to school,7.7 \%of mothers of respondents have only studied up to $2^{\text {nd }}$ standard, For $6.3 \%$ the education is below $7^{\text {th }}$ class, $50.2 \%$ studied upto $9^{\text {th }}$ standard $20.1 \%$ completed $10^{\text {th }}$ class and remaining $2 \%$ of mothers have higher secondary education. None of the mother of respondents have studied above high school. Among the respondents, the number of parents who achieved above higher secondary education is nil, indicating their marginalization at these levels.

Considering the occupation of the father of respondents, $3.3 \%$ are government employees, 16.7 $\%$ doing private jobs, $63.3 \%$ are daily wage laborers, $16.7 \%$ are farmers.

$13.3 \%$ of the mothers of respondents are doing private job, $30 \%$ of the mothers' are daily wage labors and remaining $56.7 \%$ are house wives. $5 \%$ of the respondents want their mother to go to job because of financial problems. Considering the source of income of a family, For 55.0\% of 
International Journal of Social Science and Economic Research

ISSN: $2455-8834$

Volume: 05, Issue: 06 "June 2020"

the respondents, main income source is from father's job, for $11.7 \%$ from mothers job, for $26.7 \%$ from the job of both father and mother and for the remaining $6.7 \%$ respondent is also a contributor of income together with both parents. Among the respondents who earn their livelihood, $12.2 \%$ of the respondents are going for a job for need of personal income. All respondents come under BPL category. All the respondents are residing in rural area.

\subsection{Educational facilities in tribal areas}

It is opined by $82 \%$ of the respondents that the anganwadis functioning in tribal areas lack basic infrastructure and facilities. Proper pre-schooling in tribal areas will certainly help to imbibe an affinity towards education at the very young age and bring down the dropout rate at school levels.

$12.6 \%$ of the respondents are studying in single teacher schools.

5.6 Social, economic, cultural and institutional factors of the tribes determining the dropout of tribal students from schools.

$68.3 \%$ of respondents are still studying in school; the remaining $31.7 \%$ of children are not studying now. Out of the $31.7 \%$ dropout students, $42 \%$ are dropped out at Lower Primary level, $11.3 \%$ students dropped out at Upper Primary level and the remaining $12.5 \%$ are those students who dropped out during High school level,34.2\% dropped out at higher secondary level.

In most cases, the decision to dropout was taken by the students themselves. About 94.8 percent of the dropout respondents replied that decision to drop out from school was their own. 90.2 percent of the respondents who decided to drop out from school by their own, mentioned that daily travelling of long distance to reach the school, difficulty in comprehending taught subjects and disinterest in studies are the reasons of their dropout.

Remaining 5.2 percent of the respondents mentioned that it was due to the influence from the persons such as father, mother and teacher which made them to discontinue from their studies. Among the students, who dropped education by the influence of others, 66.1 percent mentioned that their father insisted them on dropping out from the school. 22.1 percent cases mentioned that they have dropped out from the school by the influence of their mother. The reason for the students, who dropped education by the influence of parents is financial shortage.11.8 percent respondents mentioned that teacher influenced the students to stop schooling. Although majority of them are dropped out from the government schools and tribal schools, we cannot make a conclusion on the nature of school as a determinant factor of dropouts. 


\section{International Journal of Social Science and Economic Research}

ISSN: $2455-8834$

Volume: 05, Issue: 06 "June 2020"

For both upper primary and lower primary levels, the students are facing physical inaccessibility but it is more at upper primary levels. $12.6 \%$ of respondents need to travel more than $5 \mathrm{~km}$ to reach a nearby upper primary school.

Tribal students are facing severe physical inaccessibility at secondary level of education. In both districts, in the settlements studied, majority of the secondary and higher secondary institutions are located more than 5 kilometers of reach. In Idukki district, 61.5 percent of the respondents need to travel more than $5 \mathrm{~km}$ to reach high school and 64.1 percent of the respondents need to travel more than $5 \mathrm{~km}$ to reach higher secondary educational institution.

\section{SUGGESTIONS}

The tribes of Kerala have innumerable inconveniences to effectively exercise their right to education. Many hassles are encountered by them that avert them in attending classes and complete schooling in contemporary scenario. The availability, accessibility, affordability and attitude towards education and educational facilities have to be improved in tribal communities, to ensure their overall human development and improved Quality of Life. The following are the suggestions to improve the education of the tribals.

- An effective early childhood education could improve the enrolment at school levels. Proper pre-schooling in tribal areas will certainly help to imbibe an affinity towards education at the very young age and bring down the dropout rate at school levels.

- Parents should become aware about the importance of education, monitor the studies of children provide encouragement and engage the children academically and intellectually at home and motivate them. Besides, parental involvements in the studies to be encouraged by way of attending PTA meetings.

- Better school environment should be provided for tribal students. Basic infrastructures of the tribal schools have to be improved.

- Physical inaccessibility to school is still a major challenge faced by the tribal students. The government should ensure that the tribal students are able to achieve compulsory elementary education as proposed under the Right to Education Act, 2009. Physical inaccessibility to secondary level schooling can be resolved to a great extent by setting up adequate hostel facilities near the school.

- The qualifications for the eligibility for the post of instructor or teacher for the schools in tribal areas are lowered due to inability to find suitable candidates from these areas. This problem may be resolved by framing policies to extend compulsory service by the government teachers to tribal and remote rural areas.

- Teachers in the tribal schools should be well equipped with pedagogy. In schools, teachers should provide student friendly environment, follow student centered approach and provide 


\section{International Journal of Social Science and Economic Research}

ISSN: $2455-8834$

Volume: 05, Issue: 06 "June 2020"

an arena for the holistic development of the student. Teachers in the tribal schools should be knowledgeable about the tribal customs, problems, culture and social interactions of the tribal community.

- Remedial education and special tutoring for selected subjects should be given at higher levels of schooling, by which comprehension of these subjects could be resolved.

- There exists difference in the language they normally speak within the community and the medium of instruction followed in schools which are normally in regional language. The students should be encouraged to cope up with regional language and thereby reduce the problem with medium of instruction.

- The teachers in the tribal schools should be given the autonomy to reasonable extent to modify the curriculum of the tribal schools at par with the language limits and comprehension ability of the students.

- Many tribal families incur higher costs in sending their children to the school. It is essential to increase the amount paid as lump-sum grant. Travel allowance should be provided for parents to attend the PTA meetings and to visit the students in residential facility.

- There is a dare need for more educational schemes and educational grants for tribal students. Educational schemes should address problems in tribal education such as high school dropout rate, low enrolment at secondary level, poor performance at higher education etc.

- Criteria for fixing up the value of grants should be revised periodically. Provision for personalised assessment to be made to finalise the amount of grants depending on the individual's situation.

\section{LIMITATIONS OF THE STUDY}

The study is conducted in districts of Kerala such as Wayanad ,Palaghat and Idukki, where the infrastructure of roads and transportation facilities are poor. Hence the researcher faced difficulty in accessing habitations of tribes located in remote areas. Lack of proper information on school dropouts from the education department authorities was another hurdle associated with the study. The researcher faced much difficulty in identifying and contacting dropout students. The existence of difference in culture, religious belief, nature and remoteness of habitation and dialect restrict the researcher from making generalization of results across the whole state.

\section{CONCLUSION}

Studies on tribal education in India particularly focused on various aspects such as policies and programmes implemented for dealing with educational backwardness of tribal students, factors affecting the education of students, literacy, etc. As Scheduled Tribes are considered 


\section{International Journal of Social Science and Economic Research}

ISSN: $2455-8834$

Volume: 05, Issue: 06 "June 2020"

marginalized groups residing in interiors of forests and far away from the mainstream population, they require proper education to develop the human resources necessary for economic and social transformation.

\section{REFERENCES}

Agrawal, Pawan (2009). Indian Higher Education: Envisioning the future. Sage Publications: New Delhi.

Bala, Suman (2011). Influence of Parental Education and Parental Occupationon Academic Achievement of Students. International Shodh Samiksha Aur Mulyankan, July, 3(30).

Census of India (2011), Registrar General and Census Commissioner, Government of India.

Choudhury, Amit (2006). Revisiting Dropouts: Old Issues, Fresh Perspectives. Economic and Political Weekly, December, 5257-5263.

Darpika, Shyamal Kumar.(2017). Tribal education in India- Government Initiative and Challenges, International Journal Of Research In Social Science, 7(10) 156- 165.

Duary, N K (2010). Education in Tribal India, Mittal Publications, New Delhi.

Dunn, Dana (1993). Gender inequality in education and employment in the scheduled castes and tribes of India. Population Research and PolicyReview,12(1), p. 53-70.

Government of India. (2011). Annual Report 2010-11. Ministry of Tribal Affairs, New Delhi.

Government of India. (2016). Economic Review, Kerala State Planning Board, Thiruvananthapuram.

Kolay, S.K. and Bairagi, R. Maternal and Child Health care Practices and their associated Sociocultural and environmental Factors: A Micro Level Study among Muria tribe in Bastar district of Chhattisgarh. A book chapter in the book on "Ethnomedical Practices in Tribal Areas", SSDN Publishers and Distributors, New Delhi, J, Dash, P.K. Patra and K.C. Satpathy(Eds), (2013), 281-300.

Manjunatha, Annapurna( 2012). An Investigative Study on School Dropouts in Tribal Settings A Case of Three selected Tribes in South Karnataka. Journal of Anthropology, 8(2).

Mitra, A., \& Singh, P. (2008). Trends in literacy rates and schooling amongthe scheduled tribe women in India. International Journal Of Social Economics, 35(1/2),p. 99-110. 
Omanaseelan, M (2002). Status of Formal and Non-Formal Education programme prevalent for Scheduled Tribe students in Kerala. PhD Thesis submitted Mahatma Gandhi University, Kottayam, Kerala.

Rathnaiah, E V (1977). Structural constraints in Tribal Education: A regional study. Sterling Publishers Pvt. Ltd., New Delhi.

Saxena, Alka (2002). Dynamics of tribal education, Rajat Publications: NewDelhi.

Tharakan, .P K. M. (2000). Community Participation in School Education-Experiments in the State of Kerala.: Kerala Institute of Local Administration (KILA).

The Hindu.(2006). Tribal Education Needs a Holistic Approach. http://www.thehindu.com/2006/05/29/stories/2006052906830300.htm accessed on 28/07/2019.

V.A, Haseena \& P. Mohammad.(2014). Scope of education and drop out among tribal students in Kerala Study on the scheduled tribes in Attappady, International Journal Of Scientific And Research Publications, 4, (1),p.1-13.

Zacharias, Sibi (2003). The micro-level impact of tribal development programmes among the Kadar tribe of Kerala. Project report, Kerala Research Programme on Local Level Development, Centre for Development Studies, Thiruvananthapuram. 